\title{
Calendário agrícola, agrobiodiversidade e distribuição espacial de roçados Kulina (Madija), Alto Rio Envira, Acre, Brasil
}

\author{
Moacir Haverroth* \& Paula Rosane Menezes Negreiros
}

Embrapa Acre, Rodovia BR-364, Km 14, Caixa Postal 321, 69.908-970, Rio Branco, Acre, Brasil.

\begin{abstract}
Resumo - O presente trabalho objetiva avaliar a composição e distribuição espacial e temporal de roçados entre os Kulina (Madija) do Alto Rio Envira, estado do Acre, sudoeste da Amazônia Brasileira. A população estudada vive em aldeias às margens do rio Envira, distribuídas em três Terras Indígenas, e sua língua pertence à família linguística Arawá. A pesquisa de campo foi realizada com base em entrevistas semiestruturadas e abertas, observação direta e participante, marcação dos roçados com aparelho de GPS e fotografias. Foram observados 64 roçados, com áreas que variam de $50 \mathrm{~m}^{2}$ até 2 ha. São cultivadas entre 3 e 15 espécies em cada roçado. O calendário agrícola segue a sazonalidade regional. O trabalho nos roçados envolve a abertura, ano após ano, de novos espaços de cultivo, tendo em vista a manutenção das plantas cultivadas e a produção de alimentos. O sistema de cultivo segue o ciclo roça-capoeira-floresta, integrado em mosaico com outros espaços da floresta. Além das áreas florestais, são aproveitadas as praias para cultivo de algumas espécies. Os roçados, a despeito do uso do fogo, seguem alguns princípios agroflorestais sucessionais e contribuem para a conservação da agrobiodiversidade e recomposição da floresta. As áreas abertas para cultivo são relativamente pequenas e, após o “abandono", como está cercada pela floresta, rapidamente ocorre a regeneração florestal.
\end{abstract}

Palavras-chave adicionais: agricultura indígena, índios sul americanos, roças.

\begin{abstract}
The agricultural calendar, agro-biodiversity and spatial distribution of the Kulina (Madija) clearings, Upper Envira River, Acre, Brazil) - The present study aims to evaluate the composition and spatial and temporal distribution of indigenous clearings amongst the Kulina (Madija) from Upper Envira River, Acre State, southwestern Brazilian Amazon. The studied population lives in villages on the banks of the Envira River, distributed in three Terras Indígenas (Indigenous Lands), and their language belongs to the Arawá linguistic family. Field research was based on semi-structured and open interviews, direct and participant observation, recording the clearings with GPS equipment and photographs. We observed 64 clearings, with areas ranging from $50 \mathrm{~m}^{2}$ to 2 ha. Between three and fifteen species are cultivated in each clearing. The agricultural calendar follows the regional seasonality. Every year the Kulina open up new clearings for cultivation in order to maintain crops and food production. The system follows the cycle clearings - capoeira (initial stage of forest succession) - producing a forest mosaic. Apart from the forests, beaches are used for cultivation of some species. The clearings, despite the use of fire to open clearings, follow successional agroforestry principles and contribute to conservation of agro-biodiversity and to forest regeneration. Areas opened for cultivation are relatively small and, after being abandoned, forest regeneration occurs quickly because they are surrounded by forest.
\end{abstract}

Additional key words: clearings, indigenous agriculture, South American Indians, swiddens.

Na Bacia Amazônica, as populações humanas que tradicionalmente habitam a floresta usam seus recursos naturais de diversas maneiras (Barros et al. 2011); dentre estas, podemos incluir a caça e a coleta de frutos e plantas silvestres, principalmente para uso terapêutico e alimentar. No entanto, práticas e conhecimentos agrícolas tradicionais continuam sendo a base para a maior parte da produção primária de alimentos numa boa parte do mundo rural atual (Gliessman 2009).

Muitas práticas tradicionais na agricultura dependem de um conhecimento ecológico local profundo (Capra 2007), característica que podemos atribuir aos sistemas de conhecimento indígena. De fato, os povos indígenas apresentam amplo conhecimento sobre o manejo de sistemas ecológicos complexos, melhorando e cultivando fontes alternativas de produtos naturais e, devido à sua estreita

Autor para correspondência: moacir.haverroth@cpafac.embrapa.br Editora responsável: Cecília de Fatima C. B. Rangel de Almeida

Recebido: 16 maio 2011; aceito: 11 ago. 2011. relação com estes, desenvolveram diferentes estratégias de adaptação que, em muitos casos, contribuem para o aumento da biodiversidade em todos os biomas vegetais por eles habitados (Balée 1992; Ming 1997; Pedri 2006), o que tem sido analisado pela distribuição espacial das espécies (Hernandez-Stefanoni et al. 2006). Neste sentido, Reichhardt et al. (1994), a partir de estudo quantiativo e comparativo, afirmam que a riqueza de espécies nos complexos hábitats agrícolas pode ser maior que a das áreas naturais. Porém, conforme Haverkort \& Millar (1994), isso depende da manutenção ou fortalecimento dos sistemas culturais que prevalecem na área.

Essa relação estreita entre as populações humanas e a estrutura de florestas tropicais tem grande influência da prática da agricultura, a qual implica inevitavelmente na existência de áreas abertas ou, na falta destas, na abertura de clareiras na floresta para o cultivo organizado de espécies úteis ao homem, principalmente para a alimentação. As comunidades autóctones souberam desenvolver tecnologias adaptadas às condições ambientais, sociais e 
culturais locais, mesmo que em áreas relativamente pequenas e atendendo a populações também restritas (Ming 1997).

Essa realidade é característica de povos indígenas amazônicos que praticam a agricultura itinerante, definida como um sistema agrícola no qual os cultivos são feitos por um período inferior ao que permanecem em pousio (Moran 1994), como tem sido demonstrado por diversos estudos, como entre os Kayapó (Posey 1984, 1987; Anderson \& Posey 1989), entre os índios da Bacia do Rio Negro (Ribeiro 1995) e entre os Deni do estado do Amazonas (Noda et al. 2003; Pezzuti \& Chaves 2009).

Com relação aos aspectos espaço-temporais de roçados indígenas, estudos foram feitos entre indígenas do Brasil, como os Desana da Bacia do Rio Negro (Ribeiro \& Tolamãn Kenhiri 1989), entre os indígenas no rio Cueiras, no Baixo Rio Negro, Amazonas (Cardoso 2008), entre os Assurini (Ribeiro 2009) e demais grupos indígenas do Xingu (Faraldo et al. 2000). São bem conhecidos também os trabalhos de Toledo et al. (1994, 2003) e Toledo (2001) entre indígenas do México. A relação entre o cultivo do milho (Zea mays L.) e os fatores socioculturais e religiosos foi estudada entre indígenas de Santa Catarina e de Roraima (Pedri 2006). Em Araujo \& Verdum (2010), experiências de Assistência Técnica e Extensão Rural entre indígenas são analisadas, indicando desencontros históricos entre políticas aplicadas visando a produção e o desafio da interculturalidade e metodologia participativa que hoje se estabelece para a compreensão dos modos tradicionais de agricultura indígena.

O objetivo deste estudo foi analisar a composição e distribuição de roçados em três Terras Indígenas (TI) da etnia Kulina do Alto Rio Envira, estado do Acre, e descrever o calendário das principais atividades relacionadas aos roçados.

\section{Métodos}

Esta pesquisa foi autorizada pelo Conselho de Gestão do Patrimônio Genético (CGEN) do Ministério do Meio Ambiente (MMA) do Brasil (Processo n ${ }^{\circ}$ 02000.003320/200641 , Deliberação $n^{\circ} 232$, publicado no Diário Oficial da União em 16/12/2008 - Seção 1 - Pág. 109). A anuência prévia dos Kulina foi obtida em dezembro de 2006, em viagem de campo realizada exclusivamente com essa finalidade. Após autorização do CGEN, a FUNAI emitiu "autorização definitiva" de ingresso nas TI do projeto durante sua vigência. Todas as viagens foram acompanhadas por pelo menos um representante da OPIRE (Organização dos Povos Indígenas do Rio Envira).

Área do estudo. A pesquisa de campo foi realizada nas TI Kulina do Igarapé do Pau (45.590 ha), Kulina do Rio Envira (84.365 ha) e Jaminawa-Envira (80.618 ha), localizadas no Alto Rio Envira, afluente do rio Juruá, município de Feijó,
Acre, Amazônia brasileira (Figura 1). A cidade de Feijó está situada a $384 \mathrm{~km}$ de Rio Branco, capital do Acre e apresenta temperatura média anual de $24,5^{\circ} \mathrm{C}$. A precipitação no Acre varia de 1.600 a $2.750 \mathrm{~mm}$ anuais (Acre 2009). Nas TI pesquisadas, a altitude varia de 210 a $240 \mathrm{~m}$ entre a parte mais à jusante e mais à montante, desde os limites da TI Kulina do Igarapé do Pau até a TI Kulina do Rio Envira, respectivamente, segundo dados coletados com aparelho receptor de GPS durante a pesquisa.

A população nas três TI, em novembro e dezembro de 2008, foi de 423 pessoas, distribuída em 77 casas de 10 aldeias, sendo que $51 \%$ têm menos de 15 anos de idade e os idosos são raros (Figura 2). A ocupação das casas varia de duas a dez pessoas. Esse perfil demonstra alta taxa de natalidade, mas baixa expectativa de vida. A proporção entre sexos é de $49,7 \%$ mulheres para 50,3\% homens.

Com relação à idade, em muitos casos, o que se faz é uma aproximação da data de nascimento devido à falta de registro ou qualquer outro documento. Nesses casos, recorre-se a informações dos familiares. A data de nascimento não tem importância para os Kulina, exceto quando se torna necessária para solicitar a aposentadoria, processo que exige documentação pessoal regular.

Há forte endocruzamento, mas há alguns casamentos interétnicos, especialmente com os Kampa (Ashaninka), que também habitam nessa região do Envira, e com não-indígenas (cariú).

As doenças mais prevalentes entre os kulina são as de veiculação hídrica e alimentar e as infecções respiratórias agudas. Entre as primeiras, destacam-se as diarréias (mimiji), principalmente entre crianças, e verminoses (ssomi). Outros problemas importantes são acidentes ofídicos, acidentes durante atividades nos roçados (principalmente na etapa de derruba e queima) e na floresta (durante atividade de caça), ferimentos consequentes de conflitos internos e dermatoses em geral.

Um problema estritamente ligado a questões culturais dos kulina são as acusações mútuas, entre membros de diferentes aldeias, de dori, uma categoria etiológica ligada ao xamanismo, aspecto importante da cultura kulina. Cada aldeia tem um ou mais xamãs (dsopineje), que atuam tanto em tratamento e cura como também são constantemente acusados de provocar dori, problema que requer a atuação de outro dsopineje para desfazê-lo.

O itinerário terapêutico depende das opções disponíveis e que estejam mais facilmente ao alcance da população. Entre os kulina do Alto Envira, devido ao isolamento em relação à cidade, onde se concentram os serviços oficiais de saúde, os recursos se restringem praticamente àqueles disponíveis na floresta e que são de seu conhecimento, além da atuação dos xamãs. Não há postos de saúde nas aldeias. Somente casos mais graves e reconhecidamente provocados por fontes estranhas ao universo kulina é que são encaminhados para a cidade de Feijó ou, seguindo o fluxo de maior gravidade, para a capital, 


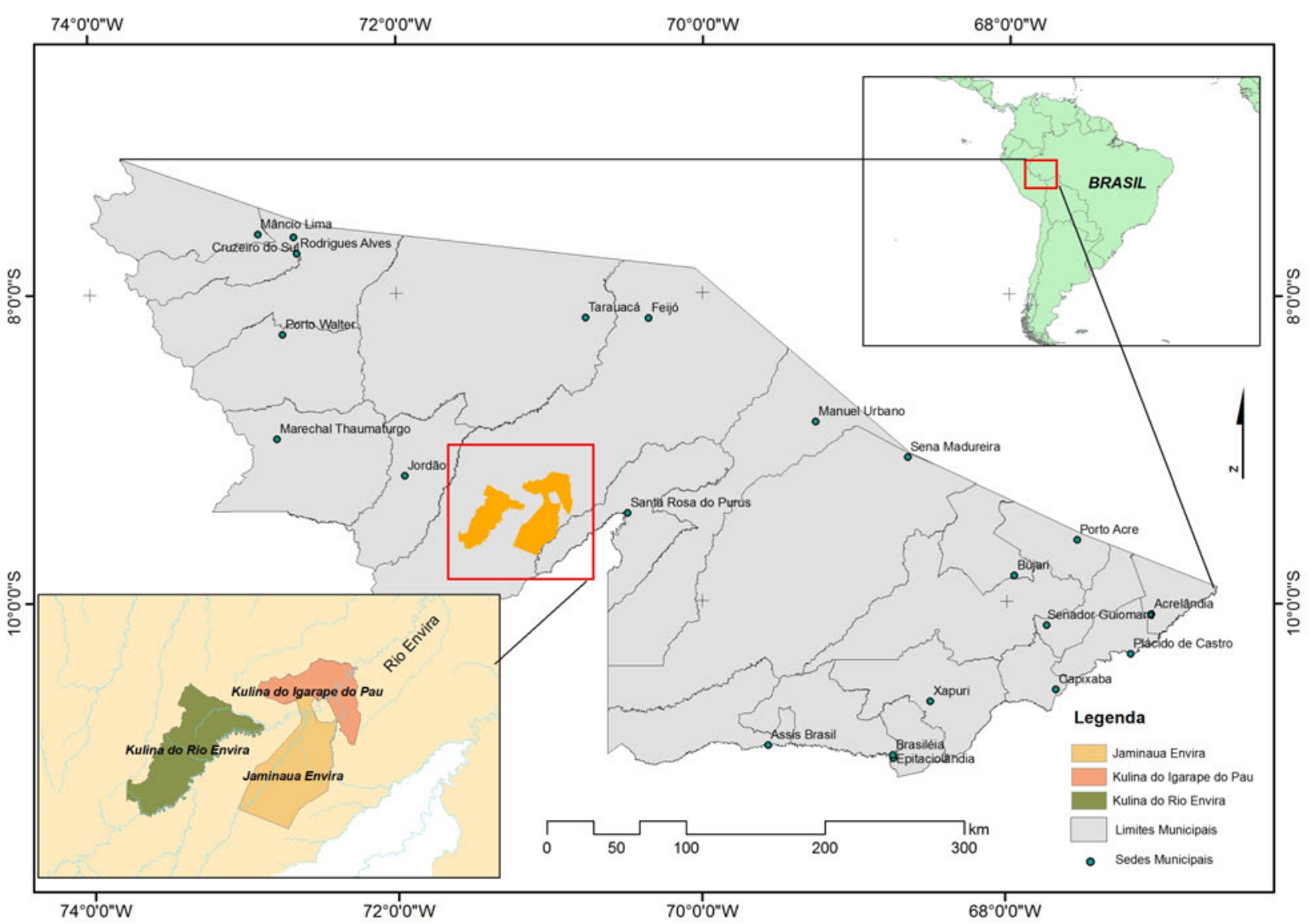

Figura 1. Localização das Terras Indígenas Kulina do Rio Envira, Jaminawa-Envira e Kulina do Igarapé do Pau, da etnia Kulina (Madija), no Alto Rio Envira, município de Feijó, estado do Acre, Brasil.

\section{Rio Branco.}

As espécies mais importantes como caça são o porquinho [Tayassu tajacu (Linnaeus, 1758)], o queixada [Tayassu pecari (Link, 1795)], o veado (Mazama spp.), a anta [Tapirus terrestris (Linnaeus, 1758)], a capivara (Hydrochoerus hydrochaeris Linnaeus, 1766), várias espécies de primatas e outras espécies menores, como paca (Cuniculus paca Linnaeus, 1766), cotia (Dasyprocta aguti Linnaeus, 1766), jabuti (Testudo sp.) e tracajá (Podocnemis sp.). O jacaré (Caiman spp.) também é muito visado pelos kulina e são caçados à noite com uso de arpão ou arma de fogo.

A pesca é uma atividade rotineira e representa uma fonte alimentar mais acessível e que demanda menor esforço que a caça. Porém, depende da época do ano, devido ao nível das águas, da disponibilidade de lagos próximos da aldeia e de instrumentos de pesca apropriados e em boas condições.

A criação de animais é uma atividade incipiente. Dependendo da aldeia, são criadas algumas espécies domésticas introduzidas, como suínos (Sus domesticus Linnaeus, 1758), bovinos (Bos sp.), carneiro (Ovis sp.) e galinhas (Gallus gallus domesticus Linnaeus, 1758), além do cachorro (Canis lupus familiaris Linnaeus, 1758), utilizado como auxiliar na caça ou apenas como animal de estimação. Várias espécies animais nativas da floresta podem ser encontradas numa aldeia kulina. Geralmente, são filhotes

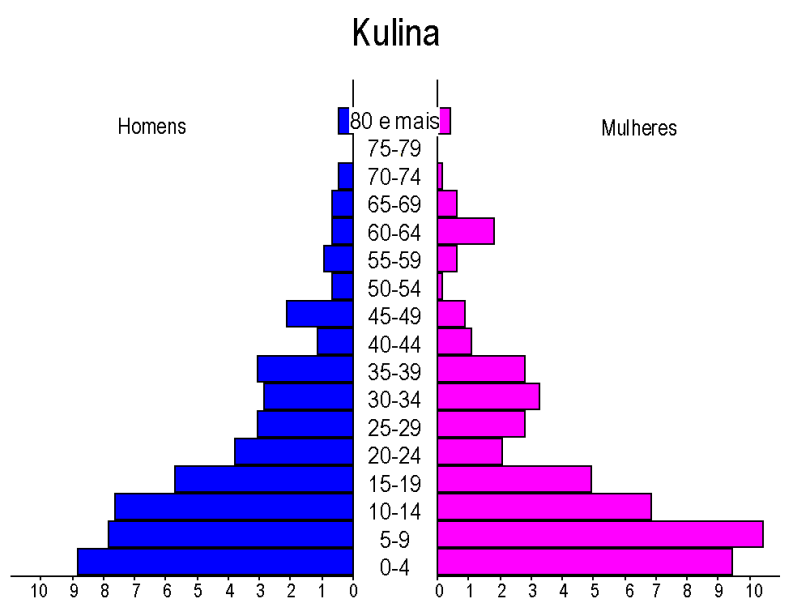

Figura 2. Pirâmide populacional dos Kulina (Terras Indígenas Kulina do Igarapé do Pau, Jaminawa-Envira e Kulina do Rio Envira), no Alto Rio Envira, município de Feijó, estado do Acre, Brasil, em dezembro de 2008, em percentagem $(\mathrm{n}=423)$ (EPIDAT 3.1 Software). 
de animais caçados que são trazidos para casa e tornam-se elementos comuns no cotidiano doméstico.

Em geral, as aldeias são compostas apenas pelas casas de moradia. Das 10 aldeias das três TI pesquisadas, apenas uma possui uma construção destinada à escola, onde atua um professor cariú (não-indígena) que mora na aldeia. Nas demais, há professores, mas não há construção específica para servir de escola. Normalmente, a aula acontece nas casas dos professores. Em apenas duas aldeias há professores kulina contratados pelo Estado. Em geral, os Kulina sabem ler e escrever em sua própria língua, fruto de um trabalho de alfabetização desenvolvido nos anos de 1980 pelo Conselho Indigenista Missionário e que ainda persiste através de alguns professores kulina.

Coleta de dados. A pesquisa de campo foi realizada entre dezembro de 2008 e dezembro de 2010 . Nesse período, foram feitas quatro viagens às três TI envolvidas, com duração entre 25 e 45 dias. $\mathrm{O}$ acesso às TI do Alto Rio Envira foi feito via aérea, entre as cidades de Rio Branco e Feijó (uma hora de voo), e via fluvial, subindo o rio Envira a partir da cidade de Feijó (cinco a sete dias até a aldeia situada mais acima). Todas as viagens foram feitas na estação chuvosa ("inverno" acreano, entre outubro e abril), pois, na estação de estiagem, a navegabilidade fica restrita a pequenas embarcações tipo canoa.

A pesquisa foi feita com base em entrevistas semiestruturadas e abertas, com representantes das 77 famílias kulina levantadas, observação direta e participante (Bernard 1994), registro das áreas dos roçados em aparelho de GPS, fotografias e anotação das espécies cultivadas em cada roçado (nomenclatura na língua kulina e em português). Dos entrevistados, apenas uma foi do sexo feminino, pois as entrevistas ocorrem durante as visitas aos roçados e estas costumam ser acompanhadas pelos homens. A entrevista com a mulher aconteceu em visita a um roçado próximo à sua casa. A faixa etária dos entrevistados é variável, indo desde adultos jovens até os mais velhos.

Foram visitados e observados todos os roçados kulina existentes na época da pesquisa, num total de 64, nas três TI estudadas e cada um deles recebeu entre uma e duas visitações. Todas as incursões foram feitas acompanhadas de pelo menos um kulina, geralmente o "dono" do roçado, até equipes maiores formadas por diversos kulina de diferentes faixas etárias e gêneros, as quais apenas acompanhavam ou complementavam respostas, não havendo constrangimento entre eles já que todos os que acompanhavam são muito próximos. As entrevistas, sempre que possível, foram feitas com o "dono" do roçado ou, na ausência deste, com algum outro informante da família ou com uma liderança. Como as aldeias são pequenas, variando de quatro a quinze casas, todos conhecem muito bem todos os roçados e áreas próximas da aldeia, de maneira que, na ausência do "dono", outros informantes sempre respondiam às informações, o que era complementado pela observação direta dos roçados. As questões básicas feitas giraram em torno da época de abertura da área, época da queima, época do plantio, limpeza e colheita e espécies cultivadas, complementadas pela observação. Não foram feitas coletas de amostras de espécies cultivadas em roçados. Por se tratarem, em sua maioria, de espécies conhecidas, o reconhecimento foi feito com base na observação direta.

Em cada roçado, foram marcados pontos em aparelho de GPS, um em cada limite da área cultivada, e a área do roçado foi circundada, com aparelho de GPS marcando a linha, a fim de registrar a circunferência da área aberta e destinada ao cultivo. Após o campo, os dados de localização (coordenadas UTM), registrados em aparelho GPS, foram transferidos ao programa Trackmaker e, em seguida, foi feita a interface com imagens de satélite do Google Earth a fim de verificar a distribuição dos roçados em cada aldeia kulina ao longo do rio Envira.

\section{Resultados}

Foram visitados, observados e mapeados 64 roçados, com áreas que variam de $50 \mathrm{~m}^{2}$ até cerca de $2 \mathrm{ha}$. A maioria não passa de 1 ha; apenas dois roçados tinham dimensões maiores. Como são margeados pela floresta, logo que "abandonados", após o quarto ou quinto ano, rapidamente ocorre a regeneração da mata. O cultivo dos roçados está regido por duas estações: o 'verão', período seco que se estende, aproximadamente, de maio a outubro; e o 'inverno', estação das chuvas, que ocorre entre novembro e abril. Esse ciclo anual orienta não só o calendário sazonal das atividades ligadas à abertura (broca), derrubada, queima, plantio, limpeza e colheita, como determina as espécies de animais, peixes e frutos disponíveis em cada época e local.

Cada família possui de um a três roçados produtivos, além de algumas capoeiras, de onde continuam a extrair alguns produtos que persistem no local por algum tempo, como, por exemplo, banana, mamão, cana, manivas de mandioca e mudas de batata-doce.

Calendário agrícola. O calendário agrícola das comunidades estudadas (Figura 3) está baseado tanto na sazonalidade regional quanto na cultura dos Kulina, que se diferencia dos outros grupos que habitam o rio Envira (Kampa, Kaxinawá, Shanenawa e ribeirinhos não-indígenas). No início do verão, a partir de abril, começam a abrir as áreas ou "brocar", cortando apenas o estrato inferior da vegetação, como ervas, cipós e pequenos arbustos. Em junho e julho, fazem a derrubada das árvores. Esperam secar e, nos meses de agosto e setembro, se concentram na queimada dessas áreas. No início das chuvas, começam a plantar. Costumam fazer uma a duas capinas por ano, mas, a partir do terceiro ano, apenas controlam o crescimento de algumas plantas indesejáveis com o uso de terçado (facão). A colheita realiza-se durante todo o ano, conforme a época de produção das espécies cultivadas. $\mathrm{O}$ trabalho nos roçados envolve a abertura, ano após ano, de novos espaços 


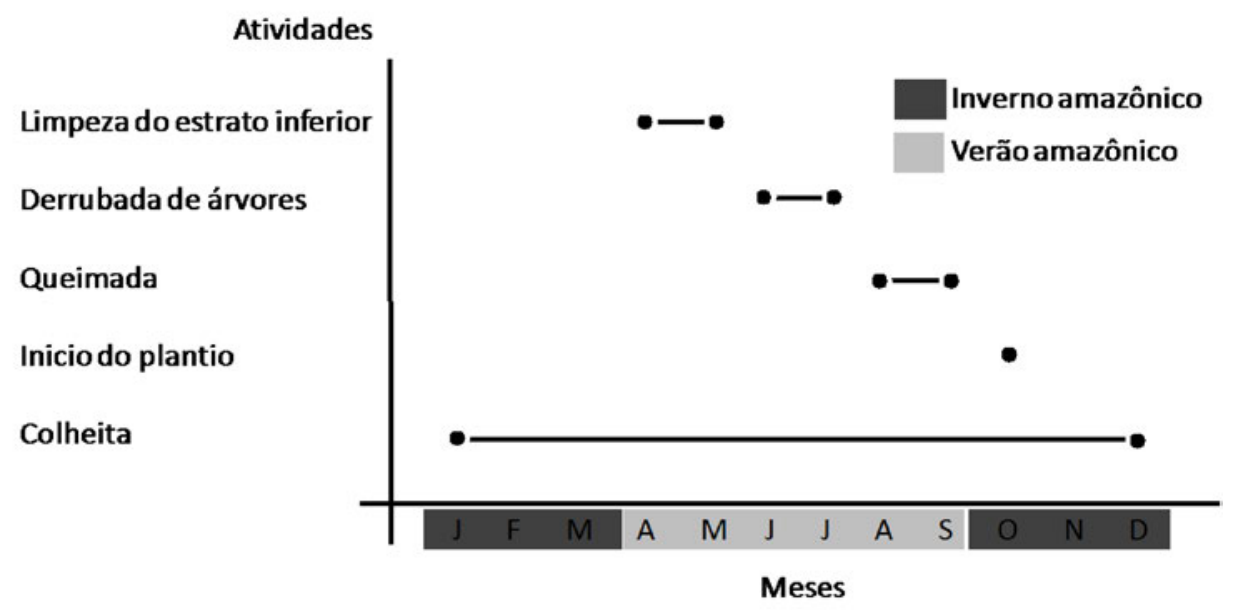

Figura 3. Principais atividades do calendário agrícola seguido pelos Kulina do Alto Rio Envira, Acre.

de cultivo, tendo em vista a manutenção das plantas cultivadas e a produção de alimentos.

$\mathrm{Na}$ época de estiagem, quando se formam grandes praias nas margens do rio Envira, os Kulina também aproveitam para cultivar algumas espécies nesses espaços. Após as cheias, grande quantidade de matéria orgânica fica depositada na areia. Nesses roçados sazonais, predomina o cultivo de feijão (Phaseolus sp.), melancia (Citrullus vulgaris Schrad.) e milho (Zea mays L.). Antes que a estação chuvosa recomece, o ciclo reprodutivo já se completou. A grande vantagem das praias é a facilidade de cultivo, pois não exige qualquer preparo da área, e o acesso, chegandose facilmente a elas remando suas canoas.

Além do cultivo, a subsistência dos Kulina também se baseia na coleta de frutos da floresta, que varia conforme a época do ano. Entre estes, destacam-se: açaí (Euterpe precatoria Mart.), buriti (Mauritia flexuosa L.), patoá (Oenocarpus bataua Mart.), cajá (Spondias sp.), cajarana (Spondias sp.) entre outros. Porém, no dia a dia, não chegam a ter peso expressivo na alimentação kulina, pois estão sujeitos à sazonalidade e podem depender de longas caminhadas para as coletas, as quais acabam sendo esporádicas, e dependem da época de frutificação de cada espécie. O mesmo já observamos entre outros indígenas regionais visitados, como os Manchineri e os Jaminawa, do rio Iaco, e os Kaxinawá e Kulina do Alto Rio Purus.

Em geral, as atividades produtivas (roçados, caça, pesca, coleta) dos Kulina são realizadas independentemente por cada família nuclear que compartilha a mesma moradia. Porém, pode haver a colaboração mútua durante a abertura de novas áreas, principalmente de mata primária, atividade que exige grande esforço. Os homens são os principais responsáveis pela abertura de novas áreas (derruba), usando apenas machado e terçado. A partir de então, as atividades são compartilhadas entre homens e mulheres, envolvendo adultos e jovens. A colheita é feita na medida da necessidade cotidiana e esse papel é, predominantemente, feminino.
Agrobiodiversidade. Entre as espécies cultivadas, há várias exóticas, as quais são trazidas quando de alguma viagem feita por algum membro da aldeia. Há troca de sementes e mudas entre os kulina e vizinhos (Ashaninka, Kaxinawá e cariú). Há intercâmbio constante com aldeias kulina do rio Purus, pois eles conhecem caminhos na floresta (varadouros) que utilizam para travessia, possibilitando troca de visitas entre moradores dos dois rios, o que pode durar vários dias de caminhada pela floresta.

Cada roçado kulina possui entre três e quinze espécies cultivadas (Tabela 1), além de outras espécies espontâneas, típicas de um processo de recomposição florística natural, que são mantidas voluntariamente ou toleradas pelos kulina. A quantificação precisa de plantas de cada espécie cultivada não foi realizada, pois a composição dos roçados é muito variada e os espaçamentos não seguem um padrão preciso. Há roçados em que as espécies são misturadas por toda a área. Em outros, além dos espaços com plantios consorciados, há pequenos espaços destinados a determinadas espécies, como tabaco, tingui e cana-deaçúcar. Entretanto, quase sempre aparecem a mandioca, a banana e o mamão, sendo que as duas primeiras em maior quantidade (Tabela 1). Culturas anuais, como milho e arroz, só aparecem em roçados novos, no primeiro ano. Após esse período, o sombreamento criado pelas culturas de ciclo mais longo impede o seu desenvolvimento. Esse fato se reflete na frequência relativamente menor dessas espécies, já que não aparecem mais nos roçados com mais de um ano.

As principais espécies cultivadas, em termos de peso na alimentação, são a mandioca, a banana e o milho. Entre as espécies cultivadas, diversas variedades podem ser encontradas. Entre as variedades locais de mandioca (poho), registramos treze: sohuehue, maccohui, huesese, eppe tohai tohai, macapa, edeni majidsadsa, appani birini, cabocca poho, amocca poho, perohana cca, cappa cca, soisa cca poho, manao cca poho, poho pohua, poho imani maconi (ou ime macohui) e poho ime pacohui caji. Para banana, foram citadas as variedades locais bare potajaro, bare

Sitientibus série Ciências Biológicas 11(2): 299-308. 2011. 
birijaro, huesese, tara, peroha, tajojo, sehoma, sapapa, bare maccoco e huahinama. Porém, a diversidade de variedades locais não foi foco desta pesquisa e requer um trabalho mais aprofundado.

Algumas espécies mais raras ou silvestres também são cultivadas, mas nem sempre nos roçados, estabelecendo-se um processo de domesticação, principalmente algumas solanáceas e famílias de monocotiledôneas, como zingiberáceas e canáceas, destas últimas sendo aproveitados os tubérculos na alimentação. Também são cultivadas, em pequena escala, plantas em torno das moradias. Entre estas, destacam-se as frutíferas e medicinais. Nesses locais, encontramos 44 espécies cultivadas; destas, 13 também estão nos roçados. Assim, os Kulina cultivam pelo menos 60 espécies entre roçados e quintais, e a alimentação pode variar de acordo com a quantidade e diversidade de plantas cultivadas.

Distribuição espacial. Os roçados kulina estão todos localizados nas margens no rio Envira (Figura 4), relativamente próximos das casas, variando desde a margem até cerca de $1500 \mathrm{~m}$, a maioria estando na faixa de até $500 \mathrm{~m}$ da margem. Porém, os caminhos nem sempre são fáceis, principalmente na estação chuvosa. Os caminhos que levam aos roçados são varadouros na mata, por onde eles caminham carregando os produtos em cestarias de folhas de palmeiras. O percurso da casa até o roçado varia, indo de poucos minutos até mais de uma hora a pé. Como os caminhos para os roçados nem sempre formam uma linha reta, as distâncias são um pouco maiores do que as medidas entre a margem do rio e o roçado (citadas acima). Na época das chuvas, com a elevação dos níveis dos rios e igarapés, alguns trechos são feitos de canoa ou, então, utilizam esse meio para apenas atravessar igarapés no meio do caminho.

O local escolhido para implantar um roçado varia de acordo com o propósito do roçado (culturas principais), tamanho, tipo e fertilidade do solo, altitude (área alagável ou terra firme) e distância das casas. Nesse sentido, próximo das casas, há roçados em áreas relativamente menores, com diâmetro de 10 a $30 \mathrm{~m}$, onde plantam, principalmente, bananeira e macaxeira. Os roçados maiores, geralmente, ficam mais distantes e são cultivados a partir da abertura de clareiras em floresta primária ou em estágio de sucessão avançado, já que próximo das moradias a mata primária é mais rara, exceto quando a aldeia é nova. Além disso, plantações próximas das moradias ficam mais sujeitas ao ataque de animais domésticos.

A ocupação do espaço pelos Kulina é bastante dinâmica, consequência de fatores internos, como conflitos, estratégia de ocupação da TI para proteção da área contra invasores, diminuição de áreas adequadas para novos roçados, identificação com moradias antigas, entre outros. Assim, quando as famílias decidem se mudar para uma nova área, quase sempre na margem do rio Envira, buscam aqueles pontos em que há boas opções de roçados o mais próximo possível das casas. Dessa forma, os primeiros plantios sempre são feitos praticamente ao lado das novas casas. Com o tempo, há necessidade de se abrir clareiras em pontos mais afastados, preferencialmente em terra firme.

As áreas "abandonadas" rapidamente entram em regeneração devido ao ambiente de floresta que as circundam. No entanto, o território onde hoje estão essas TI passou pela exploração da seringa até os anos 1970 , quando iniciou a luta pela demarcação das TI e abandono dos seringais. Muitas áreas que foram transformadas em campo pelos seringalistas já estão cobertas por mata secundária, mostrando que o modo de vida kulina atual favorece a conservação ambiental e que a abertura de novas clareiras para roçados não compromete a manutenção da floresta. As plantas são manejadas em um ciclo que imita as fases de susseção ecológica da floresta.

A distribuição dos plantios nas praias depende do tamanho destas (preferem as maiores), da proximidade da aldeia (para melhor vigiarem) e disponibilidade de sementes (guardadas dos frutos do ano anterior).

\section{Discussão Final e Conclusões}

O sistema de cultivo segue o ciclo roça-capoeirafloresta, integrado em mosaico com outros espaços da floresta, semelhante ao descrito por Cardoso (2008) no contexto do Baixo Rio Negro. Os roçados kulina são estabelecidos em pequenas extensões de terra, com tecnologias de baixo impacto ambiental e apresentando diversidade de espécies. Comparando os Kulina com os Deni, estudados por Noda et al. (2003) e Pezzuti \& Chaves (2009), a diversidade de espécies é semelhante, lembrando que os Deni pertencem à mesma família linguística (Arawá). Noda et al. (2003) anotaram o cultivo de 21 espécies nos roçados e 32 nas proximidades das moradias, totalizando 47 espécies no conjunto, ou seja, um pouco menos do que registrado entre os Kulina (29 nos roçados e 44 em torno das moradias, 60 no conjunto). Outros indígenas amazônicos apresentam agrobiodiversidade semelhante, como os Quíchua, Shiwiar e Zaparo, do Equador, com 53 espécies cultivadas em diversos ambientes (Garí 2001), e os Kayapó, com uma média de 58 espécies cultivadas por área de cultivo (Anderson \& Posey 1989). O uso de tecnologias simples e baratas, no lugar de implementos caros, também é observado entre os Kayapó (Anderson \& Posey 1989).

A observação da distribuição espaço-temporal e composição dos roçados pelos diversos estudos apontados (Ribeiro \& Tolamãn Kenhiri 1989; Toledo et al. 1994, 2003; Faraldo et al. 2000; Toledo 2001; Cardoso 2008; Ribeiro 2009) indica um modelo agrobiodiverso, onde podemos incluir os Kulina, considerando as mais de sessenta espécies que cultivam entre roçados e quintais. No entanto, a diversidade de espécies cultivadas e coletadas não garante que a alimentação do dia a dia seja diversificada durante todo o ano em função da sazonalidade local. Na maior parte do 
Tabela 1. Lista de espécies cultivadas nos roçados dos Kulina do Alto Rio Envira, Acre, contendo nome na língua kulina, nome comum em português, nome científico, família e frequência de ocorrência em 64 roçados observados.

\begin{tabular}{|c|c|c|c|c|}
\hline Nome kulina & Nome comum & Nome científico & Família & Frequência \\
\hline Poho & Macaxeira & $\begin{array}{l}\text { Manihot esculenta } \\
\text { Crantz }\end{array}$ & Euphorbiaceae & 0,92 \\
\hline Bare & Banana & Musa spp. & Musaceae & 0,79 \\
\hline Capaidso & Mamão & Carica papaya $\mathrm{L}$. & Caricaceae & 0,64 \\
\hline Majonana & Cana-de-açúcar & $\begin{array}{l}\text { Saccharum } \\
\text { officinarum } \mathrm{L} \text {. }\end{array}$ & Poaceae & 0,56 \\
\hline Bija & Cará & $\begin{array}{l}\text { Dioscorea trifida } \\
\text { L. f. }\end{array}$ & Dioscoriaceae & 0,46 \\
\hline Tapa & Milho & Zea mays $\mathrm{L}$. & Poaceae & 0,45 \\
\hline Huepe & Algodão & Gossypiит sp. & Malvaceae & 0,32 \\
\hline Jarisi & Batata-doce & $\begin{array}{l}\text { Ipomoea batatas } \\
\text { (L.) Lam. }\end{array}$ & Convolvulaceae & 0,17 \\
\hline $\begin{array}{l}\text { Huaripe/maripe, } \\
\text { huaca, satã, } \\
\text { picoma }\end{array}$ & Tingui & $\begin{array}{l}4 \text { espécies não } \\
\text { identificadas }\end{array}$ & - & 0,17 \\
\hline Mato, sirepe & Taioba & $\begin{array}{l}\text { Colocasia sp., } \\
\text { Xanthosoma sp. }\end{array}$ & Araceae & 0,15 \\
\hline Ssami, nana & Abacaxi & $\begin{array}{l}\text { Ananas comosus } \\
\text { (L.) Merr. }\end{array}$ & Bromeliaceae & 0,12 \\
\hline Sina & Tabaco & $\begin{array}{l}\text { Nicotiana Tabacum } \\
\text { L. }\end{array}$ & Solanaceae & 0,09 \\
\hline Marasidsa & Melancia & $\begin{array}{l}\text { Citrullus vulga ris } \\
\text { Schrad. }\end{array}$ & Cucurbitaceae & 0,06 \\
\hline Ajohi & Arroz & Oryza sativa $\mathrm{L}$. & Poaceae & 0,04 \\
\hline Cassi & Pimenta & Capsicum spp. & Solanaceae & 0,04 \\
\hline Imi & Ingá & Inga spp. & & 0,03 \\
\hline Toridsa, Dsoromo & Jerimum & Cucurbita spp. & Cucurbitaceae & 0,01 \\
\hline Pidsao & Feijão & Phaseolus sp. & Leguminosae & 0,01 \\
\hline- & Mucuna & Мисипа sp. & Leguminosae & 0,01 \\
\hline- & Hortelã & Mentha sp. & Labiatae & 0,01 \\
\hline Tahue & Goiaba & Psidium sp. & Myrtaceae & 0,01 \\
\hline Corimaro birijaro & Cubiu & Solanum sp. & Solanaceae & 0,01 \\
\hline Cacohuari & Mandubim/amendoim & $\begin{array}{l}\text { A rachis hypogaea } \\
\text { L. }\end{array}$ & Leguminosae & 0,01 \\
\hline Sabime & Bucha & $\begin{array}{l}\text { Luffa cylindrica } \\
\text { (L.) Roem. }\end{array}$ & Cucurbitaceae & 0,01 \\
\hline Bacate & Abacate & $\begin{array}{l}\text { Persea americana } \\
\text { Mill. }\end{array}$ & Lauraceae & 0,01 \\
\hline Amaca & Manga & $\begin{array}{l}\text { Mangifera indica } \\
\text { L. }\end{array}$ & Anacardiace ae & 0,01 \\
\hline Tohino & Gengibre & $\begin{array}{l}\text { Zingiber officinale } \\
\text { Roscoe }\end{array}$ & Zingib eraceae & 0,01 \\
\hline Casidso & Biribá & $\begin{array}{l}\text { Rollinia тисоsa } \\
\text { (Jacq.) Baill. }\end{array}$ & Annonaceae & 0,01 \\
\hline Doni & Cumaru & $\begin{array}{l}\text { Espécie não não } \\
\text { identificada }\end{array}$ & Leguminosae & 0,01 \\
\hline
\end{tabular}

tempo, os Kulina se alimentam tão somente de macaxeira e banana. Apesar de conseguirem sobreviver com o que produzem, sua produção não está de acordo com a afirmação de Gliessman (2009) de que muitos dos sistemas agrícolas tradicionais e indígenas permitem satisfazer as necessidades locais, além de contribuir no atendimento à demanda por alimentos em nível regional ou nacional.

No caso dos Kulina, eles se mantêm com o que produzem, mas estariam vulneráveis no caso de haver problemas na produção agrícola. Além disso, a distância, dificuldade de acesso e falta de política específica também impedem a comercialização de produtos agrícolas no 


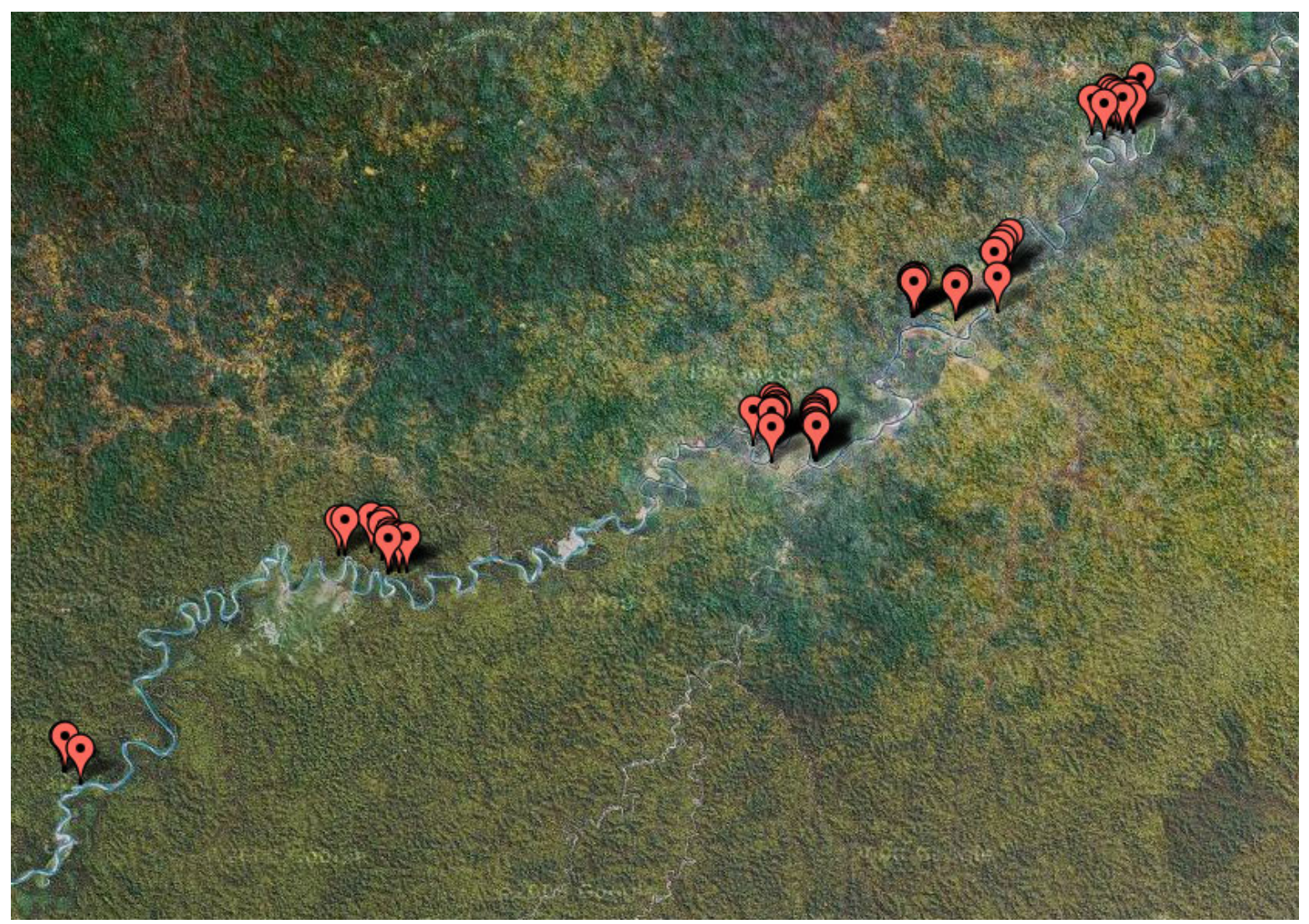

Figura 4. Representação no Google Earth® dos pontos de GPS de roçados kulina ao longo do Alto Rio Envira, Feijó, Acre. As aglomerações identificam as três Terras Indígenas dos Kulina.

mercado regional. Para conseguirem segurança alimentar e ainda poderem comercializar parte da produção, há necessidade de aplicação adequada de políticas públicas visando à diversificação da produção, a fim de atender as necessidades nutricionais, bem como possibilitando melhor acessibilidade ao mercado, já que há enormes dificuldades de acesso às aldeias do Alto Rio Envira, principalmente na época da estiagem.

A dinâmica de ocupação do espaço pelos Kulina reflete sua noção de territorialidade, na medida em que o local de moradia das famílias sofre constantes mudanças e, consequentemente, a distribuição espacial dos roçados é alterada, sendo um fator relacionado com o outro. Além de fatores internos ao grupo, ligados à cultura ou a conflitos, a gestão do território está restrita, também, aos limites das TI. O rio Envira é a referência para a construção das casas e, consequentemente, da implantação de roçados, os quais acabam se distribuindo nas faixas de terra próximas às margens do rio. $\mathrm{O}$ "centro" da mata se mantém como local de caça e coleta de produtos não cultivados. Assim, a agricultura e a caça, tal como apontado por Ribeiro (2009) para os Assurini do Médio Xingu, são as principais atividades econômicas do grupo e que garantem a maior parte da alimentação.

Nas pequenas dimensões de seus roçados, os Kulina abrigam até 15 espécies cultivadas simultaneamente, mas podemos classificá-los como roçados sucessionais, na medida em que espécies se intercalam ao longo de sua implantação e manutenção até alcançarem o estágio em que são "abandonados". Inicia-se, então, a sucessão de espécies, que passará pelos estágios de capoeira e mata secundária. Apesar do uso do fogo, esses roçados são sustentáveis do ponto de vista ambiental devido às dimensões pequenas e, como são cercados por vegetação de floresta, rapidamente acontece a regeneração da mata. Conforme Moran (1994), essas práticas de cultivo imitam, de forma simplificada, o processo de sucessão secundária da vegetação.

Essa prática concorda com Ming (1997), que coloca a agricultura de coivara ou itinerante, ainda muito praticada no Brasil, como um sistema que se baseia na compreensão do processo de recuperação natural da pequena área desmatada para sua utilização no futuro. Trata-se de uma prática agrícola branda e que permite o desenvolvimento de um complexo biológico na área após alguns anos de "repouso". Ainda segundo ele (Ming 1997), as comunidades tradicionais que usam práticas ambientalmente menos agressivas e adaptadas às condições locais são responsáveis diretas pela manutenção e conservação dos recursos genéticos dos ambientes por elas ocupadas. 
Toledo et al. (1994) chegam à mesma conclusão ao enfatizarem a importância do manejo indígena, o qual concilia com êxito produção e conservação. Essa relação pode ser estendida para a realidade kulina observada neste estudo.

Assim, é essencial reconhecer a relevância da agricultura indígena em políticas sociais. Araújo (2010) levanta o fato de que o aumento da produtividade como finalidade máxima subsidiou a Assistência Técnica e Extensão Rural (ATER) ligada à tecnificação impulsionada pela Revolução Verde, colaborando para a perda da biodiversidade e da soberania alimentar e econômica, numa crítica à política indigenista oficial quando implantava programas para tornar os indígenas "produtivos". Neste sentido, Verdum (2010) levanta o desafio da interculturalidade e da reflexão crítica sobre as ações de ATER entre povos indígenas, o que pode ser percebido nos diversos artigos publicados em Araujo \& Verdum (2010), onde fica clara a necessidade de diálogo intercultural e metodologia participativa.

\section{Agradecimentos}

Agradecemos ao povo Kulina das Terras Indígenas Kulina do Igarapé do Pau, Jaminawa-Envira e Kulina do Rio Envira; à Empresa Brasileira de Pesquisa Agropecuária (Embrapa); à Organização dos Povos Indígenas do Rio Envira (Opire); à Fundação Nacional do Índio (Funai); e à Universidade Federal do Acre (UFAC).

\section{REFERÊNCIAS}

Acre 2009. Acre em números 2009. Secretaria de Estado de Planejamento - SEPLAN, Rio Branco. Disponível em <http:/ /www.ac.gov.br>; acesso em 15 jul. 2011.

Anderson, A.B. \& Posey, D.A. 1989. Reflorestamento Indígena. Ciência Hoje 6(1): 45-50.

Araujo, A.L.O. \& Verdum, R. (orgs) 2010. Experiências de Assistência Técnica e Extensão Rural junto aos Povos Indígenas: o desafio da interculturalidade. NEAD/SAF, Brasília.

Balée, W. 1992. Indigenous history and Amazonian biodiversity. In: H.K. Streen \& Tucker (eds), Changing Tropical Forest: historical perspectives on today's challenges in Central and South America. Forest History Soicety, Duhram, p. 185-97.

Barros, F.B.; Pereira, H.M. \& Vicente, L. 2011. Use and knowledge of the razor-billed curassow Pauxi tuberosa (Spix, 1825) (Galliformes, Cracidae) by a riverine community of the Oriental Amazonia, Brazil. Journal of Ethnobiology and Ethnomedicine 7: 1.

Bernard, H.R. 1994. Research Methods in Anthropology. 2 ed. AltaMira Press, Walnut Creek.

Capra, F. 2007. A Teia da Vida: uma nova compreensão científica dos sistemas vivos. Cultrix, São Paulo.

Cardoso, T.M. 2008. Etnoecologia, Construção da Diversidade Agrícola e Manejo da Dinâmica Espaço-Temporal dos Roçados Indígenas no Rio Cuieiras, Baixo Rio Negro, Amazonas. Dissertação de Mestrado (Ciências Biológicas, Ecologia). Instituto Nacional de Pesquisa da Amazônia/ Universidade Federal do Amazonas.

Faraldo, M.I.F.; Silva, R.M.; Ando, A. \& Martins, P.S. 2000. Variabilidade genética de etnovariedades de mandioca em regiões geográficas do Brasil. Scientia Agrícola 57(3): 499505.

Garí, J.A. 2001. Biodiversity and indigenous agroecology in Amazonia: the indigenous peoples of Pastaza. Etnoecológica 5(7): 21-37.

Gliessman, S.R. 2009. Agroecologia: processos ecológicos em agricultura sustentável. Ed. Universidade/UFRGS, Porto Alegre.

Haverkort, B. \& Milllar, D. 1994. Constructing diversity: the active role of rural people in maintaining and enhancing biodiversity. Etnoecológica 2(3): 51-64.

Hernandez-Stefanoni, J.L.; Pineda, J.B. \& Valdes-Valadez,
G. 2006. Comparing the use of indigenous knowledge with classification and ordination techniques for assessing the species composition and structure of vegetation in a tropical forest. Environmental Management 37(5): 686-702.

Ming, L.C. 1997. O reconhecimento do papel das populações tradicionais no melhoramento e conservação de espécies vegetais. Horticultura Brasileira 15 (Palestra. Suplemento): 145-148.

Moran, E.F. 1994. Adaptabilidade Humana: uma introdução à antropologia ecológica. Edusp, São Paulo.

Noda, S.N.; Noda, H.; Martins, L.H.P.; Martins, A.L.U.; Paiva, M.S.S.; Mendonça, M.A.F.; Azevedo, J.H.; Neves, R.F. \& Silva, M.P.S.C. 2003. Arranjos e usos dos recursos naturais na agricultura do povo Deni. Tellus, ano 3, 4: 37-55.

Pedri, MA. 2006. A Dinâmica do Milho (Zea mays L.) nos Agroecossistemas Indígenas. Dissertação de Mestrado (Agroecossistemas). Universidade Federal de Santa Catarina.

Pezzuti, J. \& Chaves, R.P. 2009. Etnografia e manejo de recursos naturais pelos índios Deni, Amazonas, Brasil. Acta Amazonica 39(1): 121-138.

Posey, D. 1984. Os Kayapó e a natureza. Ciência Hoje 2(12): 35-41.

Posey, D. 1987. Introdução - Etnobiologia: teoria e prática; Manejo da floresta secundária, capoeiras, campos e cerrados (Kayapo); Etnoentomologia de tribos indígenas da Amazônia. In: D. Ribeiro (ed.), SUMA Etnológica Brasileira. Vol. 1 (Etnobiologia). FINEP/Vozes, Petrópolis, pp. 15-25, 173185, 251-272.

Reichhardt, K.L.; Mellink, E.; Nabhan, G.P. \& Rea, A. 1994. Habitat heterogeneity and biodiversity associated with indigenous agriculture in the Sonoran desert. Etnoecológica 2(3): 21-34.

Ribeiro, B.G. 1995. Os Indios das Águas Pretas. Edusp/ Companhia das Letras, São Paulo.

Ribeiro, B.G. \& Tolamãn Kenhíri.1989. Rainy seasons and constellations: the desána economic calendar. In: D. Posey \& W. Balée (eds), Resource Management in Amazonia: indigenous and folk strategies (Advances in Economic Botany 7): 97-114.

Ribeiro, F.A.N. 2009. Etnodesenvolvimento e o Mercado Verde na Amazônia Indígena: os Asuriní no Médio Xingu. Dissertação de Mestrado (Ciência Ambiental). Universidade

Sitientibus série Ciências Biológicas 11(2): 299-308. 2011. 
de São Paulo.

Toledo, V.M. 2001. Indigenous peoples and biodiversity. In: S.A. Levin (ed.), Encyclopedia of Biodiversity. Academic Press, San Diego.

Toledo, V.M.; Ortiz, B. \& Madellín-Morales, S. 1994. Biodiversity islands in a sea of pasturelands: indigenous resource management in the humid tropics of México. Etnoecológica 2(3): 37-49.

Toledo, V.M.; Ortiz, B.; Cortes, L.; Moguel, P. \& Ordoñez,
M.J. 2003. The multiple use of tropical forests by indigenous peoples in México: a case of adaptive management. Conservation Biology 7(3): 9.

Verdum, R., 2010. Breve esboço do indigenismo à brasileira e o desafio da interculturalidade. In: A.L.O. Araujo \& R. Verdum (orgs), Experiências de Assistência Técnica e Extensão Rural Junto aos Povos Indígenas: o desafio da interculturalidade. NEAD/SAF, Brasília, p. 14-53. 